\title{
A!
}

This is an electronic reprint of the original article.

This reprint may differ from the original in pagination and typographic detail.

Törmänen, Juha; Hämäläinen, Raimo P.; Saarinen, Esa

\section{Systems intelligence inventory}

\author{
Published in: \\ LEARNING ORGANIZATION
}

DOI:

10.1108/TLO-01-2016-0006

Published: 09/05/2016

Document Version

Peer reviewed version

Please cite the original version:

Törmänen, J., Hämäläinen, R. P., \& Saarinen, E. (2016). Systems intelligence inventory. LEARNING

ORGANIZATION, 23(4), 218-231. https://doi.org/10.1108/TLO-01-2016-0006

This material is protected by copyright and other intellectual property rights, and duplication or sale of all or part of any of the repository collections is not permitted, except that material may be duplicated by you for your research use or educational purposes in electronic or print form. You must obtain permission for any other use. Electronic or print copies may not be offered, whether for sale or otherwise to anyone who is not an authorised user. 


\title{
Systems Intelligence Inventory
}

\author{
Juha Törmänen, juha.tormanen@,aalto.fi \\ Raimo P. Hämäläinen, raimo.hamalainen@aalto.fi \\ Esa Saarinen, esa.saarinen@aalto.fi \\ Aalto University, Helsinki, Finland
}

\begin{abstract}
Purpose

Systems intelligence (SI) (Saarinen and Hämäläinen, 2004) is a construct defined as a person's ability to act intelligently within complex systems involving interaction and feedback. SI relates to our ability to act in systems and reason about systems to adaptively carry out productive actions within and with respect to systems such as organizations, family and everyday life. This paper develops an inventory to measure the SI construct.
\end{abstract}

Methodology

A combination of exploratory and confirmatory factor analysis using data from self-report questionnaires is used.

\section{Findings}

Eight factors labeled Systemic Perception, Attunement, Attitude, Spirited Discovery, Reflection, Wise Action, Positive Engagement, and Effective Responsiveness are identified as the main components of SI. SI has associations with Emotional Intelligence but also captures additional dimensions. People in supervisor positions are found to score higher in a number of the SI factors.

\section{Originality/value}

A new measure is developed to evaluate and develop our ability to succeed in systemic contexts. It is suggested to be particularly applicable in organizational contexts. This measure is directly related to the original core disciplines of the learning organization as described by Senge (1990), in particular personal mastery and systems thinking.

\section{Keywords}

Emotional intelligence, Systems intelligence, Systems thinking competence, The learning organization

\section{Introduction}

Our everyday life is embedded in systems in contexts such as work, organizations, and family. The generic set of abilities involved in the human ability to live successfully in interaction-intensive systemic environments has been conceptualized as Systems Intelligence (SI), which Saarinen and Hämäläinen (2004, p. 3) originally defined as:

"Intelligent behavior in the context of complex systems involving interaction and feedback. A subject acting with Systems Intelligence engages successfully and productively with the holistic feedback mechanisms of her environment. She perceives herself as a part of a whole, the influence of the whole upon herself as well as her own influence upon the whole. By observing her own interdependence in the feedback intensive environment, she is able to act intelligently."

This relatively broad definition integrates conceptual elements that are often held distinct. While pointing to abilities of an individual, it relates to what lies beyond the individual; while referring to an ability that the individual possesses, it points to the operational significance of that ability vis-àvis the mechanisms of the environment. Being able to function systems intelligently requires that a person is able to take into account the relevant systems and their underlying characteristics so that he or she is able to adopt and function productively in the relevant systems. 
Systems Intelligence (Saarinen and Hämäläinen, 2004, 2010) has already been used to describe the generic aspects of the meta-level skills required for succeeding in systemic settings in a number of areas such as organizations and leadership (Hämäläinen and Saarinen, 2008; Luoma et al., 2008, 2011; Saarinen, 2008), emergency management (Seppänen et al., 2013), psychotherapy (Martela and Saarinen, 2013), communications (Jones et al., 2011), and developmental studies and pedagogy (Jones and Corner, 2012; Saarinen and Lehti, 2014). The key assumption of the SI perspective is that human beings harbor abilities to adapt their actions to holistic settings, here conceptualized as systems.

The original core idea in the conceptualization of the learning organization (LO) by Senge (1990) (see also Kofman and Senge, 1993) also relates to the systemic abilities of individuals which allow learning in holistic settings with a systems perspective .There is a relatively wide literature on questionnaires which have been used to measure the learning organization (LO) and in which the focus has been on learning and on the organizational aspects. The most widely used measure is the one developed by Watkins and Marsick (1997), which also has individual level questions with a learning focus. Recently this literature has been strongly criticized by Kim et al. (2015) due to the lack of using proper psychometric analysis and validation methods. Also the earlier literature does not consider in detail the systems competences in organizations or in individuals. There are many constructs to measure organizational learning in general, but very few include the LO perspective as is done in Jerez-Gómez et al. (2005).

This paper presents a new new psychometrically validated measure that could have potential in improving the understanding and development of learning organizations. The paper also analyzes how the construct relates to Emotional Intelligence (Goleman, 1995; Salovey and Mayer, 1989), a competence which has received surprisingly little interest in the LO studies but which is yet considered to be important in organizational behavior (see e.g. Ashkanasy and Daus, 2005). We believe SI is a human core competence in the same way as the well known multiple intelligences described by Gardner (1983). The addition of the SI is motivated by its emphasis of dynamism and systemicity, which are lacking in the earlier constructs.

This paper posits that a scale including the concept of a system provides a new and rich description of people's systemic skills both in different social situations and in different contexts. The scale is suggested to relate directly to the skills required in the LO.

\section{Method}

SI is assumed to be a multifactor construct that consists of aspects such as the ability to observe and adjust one's own behavior, the ability to accurately observe and affect the behavior of others, and the abilities to find ways to improve the relevant systems both in the short term and in the long term. To capture all of these aspects, an inventory is generated consisting of a set of statements related to self, to other people, to ways of acting and reacting, and to the cognitive as well as emotional grasp of the relevant systems phenomena.

In order to account for the possibility that SI skills may differ significantly between people in different life situations, occupations, and age groups, participants were gathered from three different contexts: university students, including an open course in Philosophy and Systems Thinking and Applied Mathematics courses; employees of a large engineering company participating in an employee training event; daycare workers and managers; and an open web questionnaire.

The samples are detailed in Table 1. 
Table 1. Number of participants by sample and subsample

\begin{tabular}{|l|l||l|l|}
\hline Sample / Subsample & N & female & male \\
\hline 1.Students & 459 & 182 & 263 \\
Philosophy and Systems Thinking & 284 & 127 & 149 \\
Applied Mathematics & 175 & 55 & 114 \\
\hline 2.Daycare personnel and managers & 463 & 449 & 14 \\
Daycare personnel & 385 & 374 & 11 \\
Daycare managers & 78 & 75 & 3 \\
\hline 3. Company employees and managers & 293 & 135 & 149 \\
\hline 4. Students (following year) & 500 & 224 & 268 \\
\hline 5. Open questionnaire in English & 345 & 173 & 162 \\
\hline
\end{tabular}

\section{Study 1: Development of the SI inventory factor structure}

A list of SI-related items was iteratively worked down from an initial large set of phrases and questions that describe systems intelligent behavior. The list was refined in a series of small-scale tests, improving items that participants found too difficult, problematic, or ones that had very skewed answer distributions. This process resulted in a set of 76 pilot items.

Two data sets were created for developing the factor structure after pooling samples 1-3 together:

- A learning set $(\mathrm{N}=300)$, used for exploratory analysis, was formed by sampling 150 females and 150 males randomly among all participants.

- A validation set $(\mathrm{N}=815)$ consisted of the complete answers of the remaining participants and was used to validate the factorial validity of the inventory via confirmatory factor analysis.

Participants answered to the pilot items in Finnish with a 7-point Likert-type scale with the labels "never", "very seldom", "seldom", "sometimes", "often", "very often" and "always". In the analyses, the scale was converted to an integer scale of 0-6 respectively. The participants were allowed to leave answers to items empty. The questionnaires were administered over the internet. Participants did not get any compensation for completing the questionnaire.

Participants' SI factor scores were calculated as weighted averages of item responses, using the factor loadings from the confirmatory model.

\section{Relationship between SI and Emotional Intelligence}

The SI factor scores were associated with scores on Emotional Intelligence (Goleman, 1995; Salovey and Mayer, 1989) in a separate study with students (Sample 4 in Table 1). The participants answered 47 of the pilot items of the SI inventory in Finnish and the 33-item Schutte Self-Report Emotional Intelligence Test (Schutte et al., 1998), using a Finnish translation of the scale.

The sample size was 500 . The participants were motivated by participation in a lottery where 30 winners received two movie tickets each. The questionnaire also provided the participants a summary page that described their relative strengths and weaknesses in SI. 
In addition to the large-scale studies presented above, an English version of the inventory was provided as an open, but not actively publicized web questionnaire. The questionnaire was publicly available on a website, and people were referred to it in a number of public lectures and company training events. There were 345 participants (Sample 5 in Table 1).

\section{Results}

\section{Factor structure}

Eight of the pilot items were excluded from the analysis for highly skewed answer distributions or due to their low covariance with the rest of the items, and as such, the factor analysis was conducted with 68 items.

Exploratory factor analysis was applied to the learning dataset with the principal factors estimation method and oblimin rotation (allowing the factors to covary). The method does not entail distributional assumptions (Fabrigar et al., 1999), allowing for more robust discovery of factor structure even if some of the items don't follow multivariate normality. The analysis was conducted using the R programming language version 3.1.1 (R Core Team, 2014) and the 'psych' package (Revelle, 2014). Estimates for number of factors to retain ranged from seven provided by Horn's Parallel Analysis (Horn, 1965) to nine provided by Velicer's Minimum Average Partial method (Velicer, 1976). To better understand the factor structure, the Bass-Ackwards method (Goldberg, 2006) was applied to study how the structure develops when the number of latent factors is increased.

Based on the results of the Bass-Ackwards method, the seven-factor solution was found to have good content validity. In the nine factor solution, two factor splits were observed; one splitting attitude-related items to positively and negatively phrased factors, and another splitting interpersonal items to ones related to attuning to other people and ones related to actively changing the social system. The latter split was found to be relevant from a content perspective, and the factor structure was formed by combining the seven-factor solution with the interpersonal factor split to arrive at eight final SI factors.

To maintain good content validity and a balanced inventory, four items were selected to represent each factor in the final SI inventory. The resulting inventory thus has 32 items in total. The items and their factors are shown in Table 2. 
Table 2. SI inventory factors and items

\begin{tabular}{|l|l|}
\hline Factor & SI Item \\
\hline Systemic Perception & 1) I form a rich overall picture of situations \\
2) I easily grasp what is going on \\
3) I get a sense of what is essential to a given situation \\
4) I keep both the details and the big picture in mind
\end{tabular}

\section{Confirmatory analysis}

Structural equation modeling (Bollen, 1989) was used evaluate the factorial validity of the resulting inventory. A first-order confirmatory factor analysis model, shown in Figure 1, was estimated with the R programming language 'sem' package (Fox et al., 2014) and a Generalized Least Squares fitting function. The fit of the model was evaluated with a two-index presentation strategy suggested by $\mathrm{Hu}$ and Bentler (Hu and Bentler, 1999), picking the Comparative Fit Index (CFI) and the root mean squared residual (SRMR) as the indices. In addition, the Root Mean Square Error of Approximation (RMSEA) was included. 


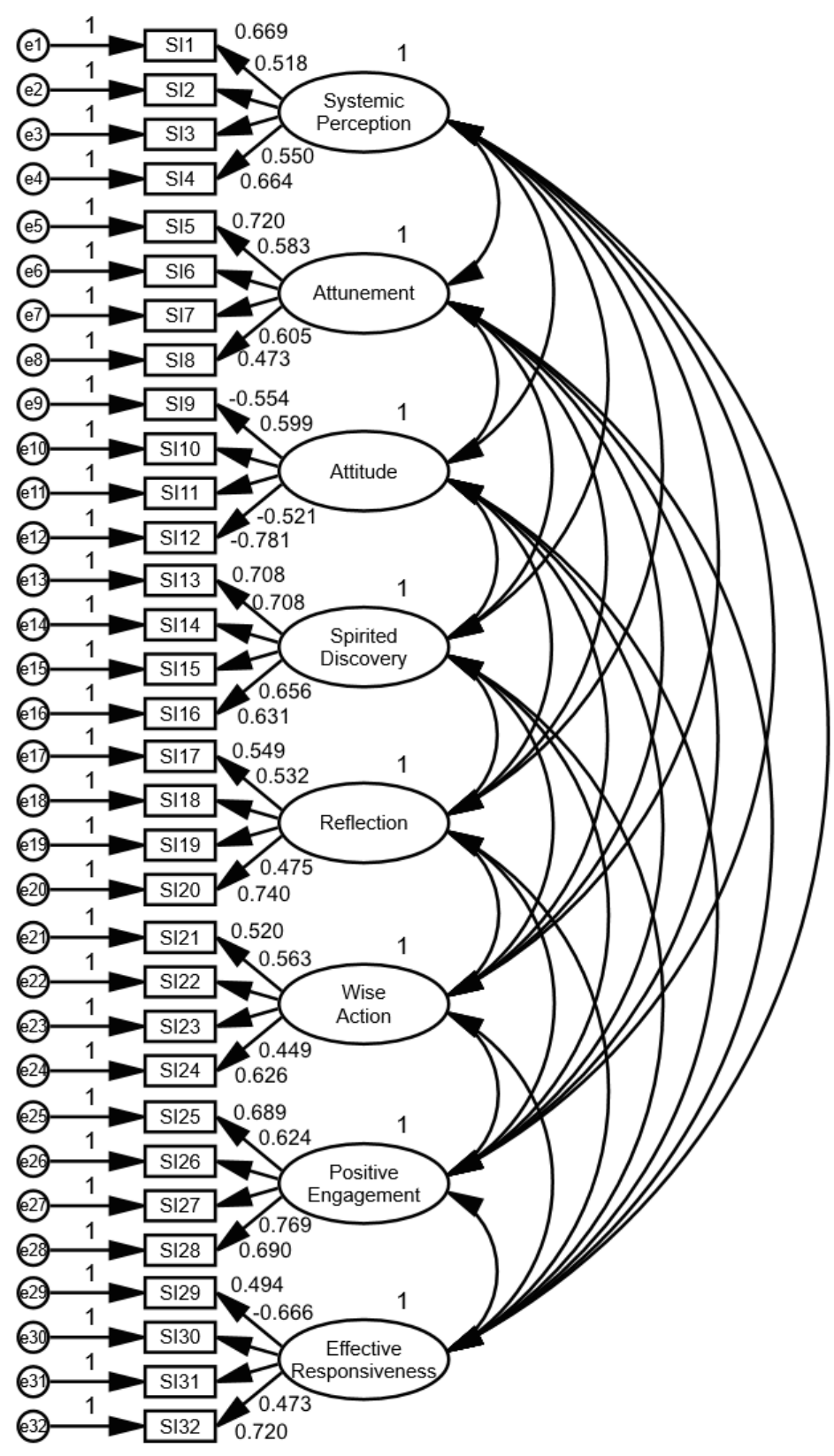

Figure 1. Eight-factor structural equation model of the SI Inventory, with calculated free-weight item loadings shown

With the 32 item loadings and variances and the 28 factor covariances set as free parameters, the model had a $\chi^{2}$ value of 1257 with 436 degrees of freedom $(p<0.001)$. The fit indices were 0.951 for CFI, 0.068 for SRMR, and 0.048 for RMSEA. All three fit indices indicated good model fit, as they were below conventional cut-off values $\mathrm{Hu}$ and Bentler suggested for rejecting badly fitting models (i.e., $\mathrm{CFI}<0.95$, SRMR $>0.08$ and RMSEA > 0.06).

Factor scores

Participants' SI factor scores were calculated as weighted averages of item responses, using factor loadings from the confirmatory model (see Figure 1). Table 3 shows the pairwise Pearson correlations and Cronbach's $\alpha$ internal consistency reliability coefficients for the factors as 
calculated by R's 'psych' package (Revelle, 2014). The table also includes pairwise correlations with Emotional Intelligence.

Table 3. Pairwise factor correlations for the SI factor scores and the Schutte Self-Report Emotional Intelligence Test. All correlations are statistically significant at level $p<0.001$. Cronbach's $\alpha$ reliability coefficients are given on the diagonal in parentheses.

\begin{tabular}{|ll|cccccccc|}
\hline & Factor & PER & ATTU & ATD & DIS & REF & WIS & ENG & EFF \\
\hline PER & Systemic Perception & $(0.83)$ & & & & & & & \\
ATTU & Attunement & 0.49 & $(0.78)$ & & & & & & \\
ATD & Attitude & 0.51 & 0.46 & $(0.67)$ & & & & & \\
DIS & Spirited Discovery & 0.61 & 0.47 & 0.43 & $(0.80)$ & & & & \\
REF & Reflection & 0.58 & 0.53 & 0.35 & 0.57 & $(0.72)$ & & & \\
WIS & Wise Action & 0.61 & 0.60 & 0.53 & 0.52 & 0.57 & $(0.64)$ & & \\
ENG & Positive Engagement & 0.55 & 0.60 & 0.46 & 0.58 & 0.49 & 0.45 & $(0.77)$ & \\
EFF & Effective & 0.63 & 0.46 & 0.57 & 0.52 & 0.43 & 0.53 & 0.50 & $(0.70)$ \\
& Responsiveness & & & & & & & & \\
\hline & Emotional Intelligence & 0.54 & 0.54 & 0.48 & 0.46 & 0.53 & 0.49 & 0.67 & 0.45 \\
\hline
\end{tabular}

The SI factor score correlations were quite high, with a range from 0.351 to 0.632 . This is an expected result, as all the factors represented skills related to Systems Intelligence and the factor structure was developed allowing the factors to covary. Internal consistency reliability scores for the factors ranged from 0.64 (WIS) to 0.83 (PER).

The correlations with the Schutte Self-Report Emotional Intelligence Test scale were also high, with a range from 0.46 to 0.67 . The most significant correlation (0.67) was between EI and SI Positive Engagement. EI and Positive Engagement correlate with other SI factors similarly, which further indicates that the two scales may be closely linked.

\section{Initial validation of the English language version}

With the English answer sample (Sample 5 in Table 1), a 'free weight' eight-factor model, identical to the model used in Study 1, had a $\chi^{2}$ value of $740(\mathrm{p}<0.001)$. Its fit indices were 0.968 for CFI, 0.085 for SRMR and 0.047 for RMSEA. Two of the three indices were below the conventional cutoff values, with SRMR being slightly higher than the suggested cutoff value of 0.08 .

\section{Group differences in SI factor scores}

The Mann-Whitney $U$-test (Mann and Whitney, 1947) was used to study how groups of participants differ with respect to the SI factor scores. Score distributions were compared between males and females, students and people who are working, and employee level and supervisor level participants. For this analysis, all samples were combined to a single $(\mathrm{N}=2060)$ data set. The twosided p-values and means for the groups are shown in Table 4. 
Table 4. Two-sided Mann-Whitney U test $p$ scores and means for compared groups

\begin{tabular}{|c|c|c|c|c|c|c|c|c|}
\hline & PER & ATT & ATD & DIS & REF & WIS & ENG & EFF \\
\hline Sex: p value & 0.6915 & **** & $0.035^{*}$ & 0.262 & $* * *$ & $0.008^{* *}$ & $* * *$ & $* * *$ \\
\hline Female mean $(\mathrm{N}=1163)$ & 4.32 & 4.60 & 3.93 & 4.31 & 4.43 & 4.22 & 4.12 & 4.36 \\
\hline Male mean $(\mathrm{N}=856)$ & 4.33 & 4.35 & 3.83 & 4.25 & 4.26 & 4.30 & 3.82 & 4.12 \\
\hline Career status: $p$ value & *** & $* * *$ & $* * *$ & $* * *$ & $* * *$ & $* * *$ & $* * *$ & $* * *$ \\
\hline At work mean $(\mathrm{N}=1304)$ & 4.41 & 4.59 & 4.02 & 4.39 & 4.41 & 4.32 & 4.16 & 4.40 \\
\hline Student mean $(\mathrm{N}=653)$ & 4.16 & 4.31 & 3.64 & 4.05 & 4.23 & 4.14 & 3.68 & 3.98 \\
\hline Supervisor status: p value & *** & 0.4479 & $0.013^{*}$ & $* * *$ & $0.004^{* *}$ & $0.003^{* *}$ & $* * *$ & $* * *$ \\
\hline Supervisor mean $(\mathrm{N}=193)$ & 4.58 & 4.68 & 4.19 & 4.58 & 4.59 & 4.48 & 4.43 & 4.66 \\
\hline Employee mean $(\mathrm{N}=826)$ & 4.39 & 4.65 & 4.04 & 4.38 & 4.41 & 4.34 & 4.17 & 4.42 \\
\hline
\end{tabular}

There were statistically significant differences in all factor scores between people at work and students, with people at work receiving higher scores. Males and females had statistically significant differences in several of the factors, with females in general providing somewhat more elevated responses than males.

People in a supervisor/managerial position had a higher score than other people at work in most factors. The difference is statistically significant at level $p<0.001$ in four of the factors, while there was no difference in Attitude scores. People in supervisor positions perceived themselves as better at perceiving and managing systems, more interested and open to new things, and better at engaging with other people in a positive way.

\section{Summary}

In today's world, people are increasingly faced with complex and systemic problems. Systems skills are becoming a key competence factor for everyone. Yet, the literature on tools to evaluate people's skills in thinking and acting successfully in systemic settings is very limited. Such tools would be most useful in particular in the development of the learning organization. This paper presents an inventory of 32 items (Table 2) to describe individual differences in SI with an eight-factor model. The factors are labeled Systemic Perception, Attunement, Attitude, Spirited Discovery, Reflection, Wise Action, Positive Engagement, and Effective Responsiveness. The SI factors identified with exploratory analysis are separate in content and are suggested to be representative of the SI concept. The resulting factor model had good factorial validity as judged by confirmatory factor analyses from samples independent from the exploratory factor analysis sample.

The SI Inventory has been designed to measure skills that are important for efficient behavior in systemic settings, rather than the personality of the participant, but it is possible that some personality traits have an effect on the SI skills. The SI factors correlate with Emotional Intelligence, with initial results suggesting that SI Positive Engagement and Emotional Intelligence are closely linked. In our data, people in a supervisor or managerial position scored higher than other people at work, especially in Systemic Perception, Spirited Discovery, Positive Engagement and Effective Responsiveness.

When the SI scale is used in organizational development and in particular in developing the skills needed in the learning organization, it may also be useful to think of the eight factors as belonging to the four general skill dimensions:

- Perceiving Systems: Systemic Perception and Attunement 
- Thinking About Systems: Reflection and Wise Action

- Systemic Attitude: Attitude and Spirited Discovery

- Action: Positive Engagement and Effective Responsiveness

The SI inventory is available at http://www.systemsintelligence.info/test/. After answering the questionnaire one gets a summary of her SI skills.

A most interesting topic for future research is to study if the SI concept could be extended to describe organizations and teams. Could we talk about organizational systems intelligence? What would be the relationships between individual and organizational SI? Could the learning organization be such that it is able to perform on a higher SI level than the average or lowest scoring individuals in it? It would also be interesting to study if people are likely to perform differently in different contexts, for example, at home as opposed to their work environment. It would also be useful to study differences in the SI scores based on self-report vs. peer-evaluations.

We do believe that introducing the concept of Systems Intelligence to people as one of our generic skills can help us develop our strengths and find ways of "being better better" (Hämäläinen et al., 2014).

\section{Bibliography}

Ashkanasy, N.M. and Daus, C.S. (2005), "Rumors of the death of emotional intelligence in organizational behavior are vastly exaggerated", Journal of Organizational Behavior, Vol. 26 No. 4, pp. 441-452.

Bollen, K.A. (1989), Structural equations with latent variables, John Wiley \& Sons, New York, US.

Fabrigar, L.R., Wegener, D.T., MacCallum, R.C. and Strahan, E.J. (1999), "Evaluating the Use of Exploratory Factor Analysis in Psychological Research”, Psychological Methods, Vol. 4 No. 3, pp. 272-299.

Fox, J., Nie, Z. and Byrnes, J. (2014), “sem: Structural Equation Models", available at: http://cran.rproject.org/package $=$ sem.

Gardner, H. (1983), Frames of Mind: The Theory of Multiple Intelligences, Basic Books, New York, US.

Goldberg, L.R. (2006), "Doing it all bass-ackwards: The development of hierarchical factor structures from the top down", Journal of Research in Personality, Vol. 40 No. 4, pp. 347358.

Goleman, D. (1995), Emotional intelligence, New York, Bantam Books, New York, US, Vol. 9.

Hämäläinen, R.P., Jones, R. and Saarinen, E. (2014), Being Better Better, Aalto University, Espoo, Finland.

Hämäläinen, R.P. and Saarinen, E. (2008), "Systems intelligence - The way forward? A note on Ackoff's 'why few organizations adopt systems thinking"', Systems Research and Behavioral Science, Vol. 25 No. 6, pp. 821-825.

Horn, J. (1965), “A rationale and test for the number of factors in factor analysis”, Psychometrika, 
Vol. 30 No. 2, pp. 179-185.

Hu, L. and Bentler, P.M. (1999), "Cutoff criteria for fit indexes in covariance structure analysis: Conventional criteria versus new alternatives", Structural Equation Modeling: A Multidisciplinary Journal, Vol. 6 No. 1, pp. 1-55.

Jerez-Gómez, P., Céspedes-Lorente, J. and Valle-Cabrera, R. (2005), “Organizational learning capability: A proposal of measurement”, Journal of Business Research, Vol. 58 No. 6, pp. $715-725$.

Jones, R. and Corner, J. (2012), "Stages and dimensions of systems intelligence", Systems Research and Behavioral Science, Vol. 29 No. 1, pp. 30-45.

Jones, R., Corner, J. and Hämäläinen, R.P. (2011), "Systems Intelligence as a Lens for Managing Personal Knowledge", in Pauleen, D.J. and Gorman, G.E. (Eds.),Personal Knowledge Management - Individual, Organization and Social Perspectives, Gower Publishing Ltd, Farnham, England, pp. 79-98.

Kim, J., Egan, T. and Tolson, H. (2015), "Examining the dimensions of the learning organization questionnaire: a review and critique of research utilizing the DLOQ", Human Resource Development Review, Vol. 14 No. 1, pp. 91-112.

Kofman, F. and Senge, P.M. (1993), "Communities of commitment: The heart of learning organizations", Organizational Dynamics, Vol. 22 No. 2, pp. 5-23.

Luoma, J., Hämäläinen, R.P. and Saarinen, E. (2008), "Perspectives on team dynamics: Meta learning and systems intelligence", Systems Research and Behavioral Science, Vol. 25 No. 6, pp. 757-767.

Luoma, J., Hämäläinen, R.P. and Saarinen, E. (2011), “Acting with systems intelligence: Integrating complex responsive processes with the systems perspective", Journal of the Operational Research Society, Vol. 62 No. 1, pp. 3-11.

Mann, H. and Whitney, D. (1947), "On a test of whether one of two random variables is stochastically larger than the other", The annals of mathematical statistics, Vol. 18 No. 1, pp. $50-60$.

Martela, F. and Saarinen, E. (2013), "The Systems Metaphor in Therapy Discourse: Introducing Systems Intelligence", Psychoanalytic Dialogues, Vol. 23 No. 1, pp. 80-101.

R Core Team. (2014), "R: A language and environment for statistical computing”, R Foundation for Statistical Computing, Vienna, Austria, available at: http://www.r-project.org.

Revelle, W. (2014), "psych: Procedures for Personality and Psychological Research", Northwestern University, Evanston, illinois, USA, available at: http://cran.r-project.org/package=psych.

Saarinen, E. (2008), "Philosophy for managers: Reflections of a practitioner", Philosophy of Management, Vol. 7, pp. S1-S24.

Saarinen, E. and Hämäläinen, R.P. (2004), "Systems Intelligence: Connecting Engineering Thinking with Human Sensitivity", Systems Intelligence - Discovering a Hidden Competence in Human Action and Organizational Life, Helsinki University of Technology, Espoo, Finland, pp. 1-29. 
Saarinen, E. and Hämäläinen, R.P. (2010), "The Originality of Systems Intelligence”, Essays on Systems Intelligence, Aalto University, School of Science and Technology, Systems Analysis Laboratory, Espoo, Finland, pp. 9-26.

Saarinen, E. and Lehti, T. (2014), "Inducing Mindfulness Through Life-Philosophical Lecturing", in Ie, A., Ngnoumen, C.T. and Langer, E.J. (Eds.),The Wiley Blackwell Handbook of Mindfulness, John Wiley \& Sons, Chichester, UK, pp. 1105-1131.

Salovey, P. and Mayer, J.D. (1989), "Emotional intelligence”, Imagination, cognition and personality, Vol. 9 No. 3, pp. 185-211.

Schutte, N.S., Malouff, J.M., Hall, L.E., Haggerty, D.J., Cooper, J.T., Golden, C.J. and Dornheim, L. (1998), "Development and validation of a measure of emotional intelligence", Personality and Individual Differences, Vol. 25, pp. 167-177.

Senge, P.M. (1990), The fifth discipline: The art and science of the learning organization, Doubleday/Currency, New York.

Seppänen, H., Mäkelä, J., Luokkala, P. and Virrantaus, K. (2013), "Developing shared situational awareness for emergency management”, Safety Science, Vol. 55, pp. 1-9.

Velicer, W.F. (1976), "Determining the number of components from the matrix of partial correlations", Psychometrika, Vol. 41 No. 3, pp. 321-327.

Watkins, K.E. and Marsick, V.J. (1997), "Dimensions of the learning organization questionnaire”, Warwick, RI: Partners for the Learning Organization. 